RERIATE ME MAALES

Campinas-SP, v.39, n.2, pp. 627-640, jul./dez. 2019

\title{
Procedimentos de Visualidade nos diários de Ricardo Piglia
}

\author{
Visuality Procedures in the \\ Diaries of Ricardo Piglia
}

\author{
Kelvin Falcão Klein ${ }^{1}$
}

\begin{abstract}
Resumo: Nos Diários de Emilio Renzi, publicados pelo escritor argentino Ricardo Piglia, em paralelo ao grande projeto de registro do cotidiano e da subjetividade, corre uma narrativa que se poderia chamar "suplementar" e que diz respeito ao contato com as imagens - fotográficas, cinematográficas ou mesmo cenas evocadas pela memória. Toda vez que a imagem é requisitada, por conta de sua materialidade ou sua ausência, Piglia articula um processo volátil de posicionamento narrativo e histórico que joga com três posições: "eu", "tu" e "ele/ela". Trata-se, portanto, de investigar como as imagens surgem nos Diários na condição de rastros, sintomas de uma espécie de condição irrefletida de estar no mundo e estar na linguagem por parte do narrador. Ou ainda, investigar como a requisição das imagens indica um caminho alternativo para a genealogia - sempre diferida e renovada - do processo de distanciamento/estranhamento tão caro a Piglia em toda a sua produção.
\end{abstract}

Palavras-chave: visualidade, diários, Ricardo Piglia.

Abstract: In the Diaries of Emilio Renzi, published by the Argentine writer Ricardo Piglia, in parallel to the great project of daily life and subjectivity record, there is a narrative that could be called "supplementary" and refers to the contact with the images - photographic, cinematographic or even scenes evoked by memory. Every time the image is requested, regarding its materiality or its absence, Piglia articulates a volatile process of narrative and historical positioning that plays with three positions: "I", "you" and "he / she". My aim is, therefore, to investigate how the images appear in the Diaries in the condition of traces and symptoms of a condition of being in the world and being in the language on the

1 Professor de Literatura Comparada na Escola de Letras da Universidade Federal do Estado do Rio de Janeiro - Unirio e do Programa de Pós-Graduação em História (PPGH) da mesma instituição: <kelvin.klein@gmail.com>. 
part of the narrator. Besides that, the aim is also to investigate how the requisition of the images indicates an alternative route to the genealogy - always deferred and renewed - of the process of estrangement so dear to Piglia in all its work.

Keywords: Visuality, Diaries, Ricardo Piglia.

\section{INTRODUÇÃO}

A ideia de abordar os diários de Emilio Renzi a partir do tema da visualidade decorre de uma constatação: a leitura desses diários desde o início mostra que, sem uma premissa inicial que limite drasticamente o material, um esforço crítico de leitura de seus três volumes corre o risco de parecer superficial ou derivativo. Além disso, os diários sempre foram referidos por Ricardo Piglia como uma espécie de parte invisível de sua obra, mas nem por isso menos presente, oscilando entre "clandestinidade" e "tradição", como aponta Sergio Waisman (2017, pp. 73-86) em artigo recente.

O próprio Piglia, em vários momentos dos diários, indica o peso do material escrito, seja reforçando sempre a data de início, o distante ano de 1957, seja apontando distintas formas de organização e apresentação do material. Já no fim do terceiro volume, por exemplo, na seção intitulada "Dias sem data", ele escreve: "gostaria de editar este diário em sequências que sigam as séries: todas as vezes que encontrei com amigos em um bar, todas as vezes que fui visitar minha mãe"; desse modo, continua ele, "seria possível alterar a causalidade cronológica. Não uma situação depois da outra, mas uma situação igual a outra. Efeito irônico da repetição" (PIGLIA, 2017, p. 271). Ou a frase de abertura do segundo tomo, quando ele escreve que "Uma vida não se divide em capítulos" (2016b p. 7).

Faz parte dos diários, portanto, a reflexão acerca do caráter amorfo dos próprios diários, que operam nesse duplo registro do relato e da interpretação do relato, "se narra e se interpreta ao mesmo tempo", como escreve Piglia (2017, p. 265) sobre o futebol. Minha exposição vai buscar exercitar esse "efeito irônico da repetição", reordenando arbitrariamente o terceiro tomo dos diários de Renzi a partir de uma atenção específica às estratégias de visualidade. A restrição ao terceiro tomo se fez necessária por uma dupla razão: em primeiro lugar, a limitação do espaço de exposição em contraste com a quantidade de material recolhido e, em segundo lugar, uma produtiva inflexão que se dá no relato diarístico de Piglia/ Renzi a partir da publicação de Respiração artificial, em 1980. Depois desse momento, a figura do escritor é solicitada com mais frequência, a 
imagem do autor, sua visibilidade no mercado editorial, na imprensa, são todos elementos de um capital simbólico que o escritor se vê na posição de manipular, com um misto de escândalo e resignação. $\mathrm{O}$ intuito aqui é o de esboçar uma genealogia possível dessa figura de escritor e de como a requisição da visualidade opera de forma determinante nesse cenário. Trata-se, contudo, de uma genealogia que busca abrir a trilha da visualidade nos diários de Renzi/Piglia não com o intuito de instaurar um ponto de origem privilegiado, pelo contrário: trata-se de uma operação "sem essência”, que visa não a "identidade ainda preservada de sua origem", mas "a discórdia entre as coisas, o disparate", segundo os termos de Michel Foucault (2010, p. 263), em seu ensaio sobre Nietzsche.

Em paralelo a isso, o terceiro tomo dos diários também articula a figura visível e pública do escritor com a invisibilidade dos desaparecidos, daqueles assassinados pelo regime ditatorial. Esse é um contraste que se apresenta pelo viés da visualidade e que configura uma das forças motrizes do relato do terceiro tomo. Já na abertura do volume surge "a visita a Antonia”, em 1978, mãe de dois desaparecidos, Eleonora e Roberto, que "tinham sido sequestrados, torturados e assassinados"; o narrador a visita e fala de uma "epifania", escreve que "no meio do espanto e do desespero e da notícia atroz que se filtrava do inferno em nossa direção, produziu-se um milagre, sem estridências, em uma conversação tranquila, em meio à dor dessa mulher, houve um momento de claridade" (PIGLIA, 2017, p. 15). Antonia discutia com a televisão e rebatia as mentiras, escreve o narrador; "na hora incerta na qual o dia se transforma", ela memorizava, revisava e repetia em voz baixa a verdade, "só peço a Deus que me deem um minuto na televisão para poder dizer como são as coisas": a televisão "repetia e ampliava a versão distorcida dos fatos", ainda o narrador, "enquanto em um apartamento modesto uma mulher pensava várias vezes em dar forma a um relato simples, certo, direto e frontal, que resumia e respondia as milhares de palavras ditas pelos canalhas" (p. 16). Um oráculo, em suma, diz o narrador, uma figura isolada diante da massa dos canalhas, retomando a tradição da Grécia clássica, especialmente a tradição de Antígona, pedindo justiça e uma sepultura digna a seus filhos. "Renzi havia tentado imaginar essas palavras e o impacto dessa voz o ajudou a sobreviver e a escrever. O silêncio da mulher - as palavras que ela pensava e não podia dizer e que ninguém escutava - era o segredo, o enigma, o que não diz mas se sabe", ou ainda, "um dizer que esperava sua oportunidade para se converter em um ato que mudaria a realidade" (p. 16). 
É a imagem desse oráculo, dessa mulher isolada diante da televisão, que inaugura o terceiro tomo do diário e repercute em todo ele, em todo o esforço de resgate dos registros dos cadernos por parte do narrador. Ele separa essa imagem da mulher diante da televisão e registra que seu impacto o ajudou a sobreviver e a escrever - escrever precisamente aquilo que estamos na iminência de ler. Além disso, a reivindicação da imagem dessa mulher-oráculo por parte do diarista é mais um elemento a reforçar a posição de Piglia dentro do amplo contexto da narrativa argentina que se faz a partir da denúncia da violência, como ocorre com Rodolfo Walsh e Luis Gusmán, por exemplo (OLMOS, 2007, pp. 105-116).

\section{O ESCRITOR COMO VIDENTE}

Mais adiante no terceiro tomo dos diários, em uma anotação de 1976, a figura do escritor se une à figura do vidente por meio de Roberto Arlt, a partir de uma releitura das Águas fortes: o modelo de Arlt vem das ciências ocultas, escreve Piglia (2017, p. 20), o escritor como vidente escreve a partir da fórmula: "estava caminhando pela rua e vi". A ideia é aprofundada quando, alguns dias depois, o narrador lê $A$ figura e o lugar, um livro do historiador da arte francês Pierre Francastel, de 1967, e chega à definição de que a arte não é um recorte do real, mas um modo de ver um modo de ver (poderíamos acrescentar) a rua, a sociedade, a política, a televisão e a tradição (PIGLIA, 2017, p. 36) -. Dias depois, o narrador se vê envolvido no "plano de revisar velhas livrarias" e, em uma delas, encontra uma antologia de ensaios de Georg Lukács. Descobre aí "um ensaio muito notável de 1913 sobre o cinema”, no qual esse autor propõe a hipótese segundo a qual "o efeito de realidade da imagem cinematográfica começa a resolver a oposição tradicional entre ficção e realidade” (p. 47). A ambiguidade do cinema invade a experiência da realidade, escreve o narrador: "a ilusão de que tudo o que se vê no cinema é real constitui implicitamente uma impressão de ambiguidade com relação ao vivido. Experiência muito clara disso é sair do cinema às três da tarde e sentir o sol como uma visão que parece continuar as luzes que se iluminam na escuridão do cinema” (p. 47).

Aqui está outro dos fios narrativos que percorrem toda a extensão do diário: a constante reflexão sobre os limites entre ficção e realidade, algo que se decompõe em uma série de outras oscilações categoriais, como nome falso e nome próprio, crítica e ficção, o escrito e o vivido, a subjetividade e a exterioridade. A cena do cinema é também constante, volta e meia 
retomada como uma sorte de metáfora da oscilação permanente entre os polos opostos. E a reflexão sobre Lukács retoma uma anotação de dias antes: "vou ao cinema à tarde e à noite para fugir das minhas próprias imagens" (PIGLIA, 2017, p. 38). O encontro com a antologia de Lukács é ao mesmo tempo um encontro fortuito, marcado pelo acaso, e também, simultaneamente, uma recompensa ao escritor vidente, que faz do seu caminho pela cidade uma busca permanente por sinais que possam ajudá-lo a ressignificar seu percurso e, por fim, alimentar a escrita da vida nos diários. A leitura teórica sobre a imagem cinematográfica, a partir de Lukács, auxilia o narrador na elaboração da sua própria ação irrefletida apontada como uma espécie de alienação autoimposta - de passar o dia no interior do cinema para escapar de suas próprias imagens.

A questão da imagem, portanto, é tanto um tema teórico que ocupa o narrador quanto um dos muitos meios utilizados por ele para pensar e repensar sua própria posição e figura como escritor, diante de si e dos outros - na escuridão anônima da sala de cinema e na visibilidade ostensiva do sol das três da tarde. No dia seguinte ao encontro com o livro de Lukács, o narrador segue na mesma linha de aproximação da questão: vai assistir Patton, salientando o excelente roteiro de Francis Coppola, e faz a seguinte anotação: "Faz alguns dias que penso várias vezes que tenho que emagrecer. Não se sabe bem qual é a razão por que me preocupo com essas coisas" (PIGLIA, 2017, p. 48). Uma reflexão aparentemente banal é já na frase seguinte exposta como uma questão definidora para a figura do escritor: o narrador não consegue se imaginar como alguém "gordo", segundo suas palavras, o que leva necessariamente a pensar "na figura imaginária de escritor que tento mostrar na sociedade. Cada vezes mais os escritores dependem de sua imagem pública e da construção de uma figura que tenha efeito e menos de seus livros" (p. 48). De novo o movimento de velamento e desvelamento da imagem se materializa no corpo do sujeito, escondido ou exposto diante do olho da sociedade e, ao mesmo tempo, manejando sua própria visibilidade a partir de uma posição de escritor - o escritor vidente que não faz um recorte da realidade, mas que propõe um modo de ver, uma perspectiva.

Já na anotação do dia seguinte, o narrador aprofunda essas reflexões em direção a uma definição geral do romance argentino. "O caráter nacional do gênero surge na autobiografia”, escreve ele, e são os "retratos" das pessoas que surgem no caminho do autor que "começam a definir um uso romanesco da narrativa pessoal", como os retratos do "rastreador" ou 
do "gaucho malo", no Facundo de Sarmiento (PIGLIA, 2017, p. 49). Trata-se aqui, da parte do narrador, da costura pouco rigorosa de uma série de elementos que articulam visualidade e relato: o romance na Argentina, segundo ele, é inseparável de uma cena inaugural no interior da autobiografia que, por sua vez, surge como um encadeamento de retratos alheios - o retrato do narrador corresponde a uma figura compósita formada pela assimilação de retratos alheios (afinal, o escritor é um vidente que não recorta o real, mas propõe um modo de ver). Dessa forma, o romance como gênero se reinventa na medida em que é bem-sucedido na tarefa de combinar familiaridade e estranhamento na apresentação dos retratos que assimila.

Um reforço dessa perspectiva é sugerido alguns dias depois, quando o narrador anota sua releitura da obra de Marcel Proust. Se antes o retrato surge como elemento de explicação do romance como gênero na Argentina, agora a fotografia propriamente dita é ligada a uma definição indireta do "clássico" na literatura - algo que antecipa, por exemplo, as investigações de Mieke Bal (1997) e sua tentativa de ler Proust "visualmente". "Fim de semana lendo Proust”, escreve Piglia (2017, p. 57), “vejo aí uma obscura origem da teoria da reprodução mecânica de Benjamin: a tia do narrador não quer fotografias. Livro notável mas, ao mesmo tempo, quando relido, tudo parece muito conhecido e quase trivial. Existem livros que nunca são lidos pela primeira vez". Vários temas reiterados ao longo dos diários surgem aqui reunidos: em primeiro lugar a reflexão sobre o clássico e os grandes livros da tradição; em segundo lugar, a menção a Walter Benjamin e a leitura que dele faz o próprio Piglia, visando a uma contextualização e problematização das vanguardas artísticas do início do século XX (algo que ele aprofunda em seu curso intitulado Las tres vanguardias, ministrado na Universidade de Buenos Aires em 1990 e recentemente publicado em livro - PIGLIA, 2016a). Além disso, a menção à "reprodução mecânica" evoca as tantas vezes que o narrador vai ao cinema, fazendo da experiência coletiva, de massa, acessível a todos, uma sorte de suspensão momentânea da própria subjetividade. A passagem parece indicar uma leitura benjaminiana do romance clássico, cuja aura é paradoxalmente reconhecida em sua capacidade de levar sempre a uma experiência de releitura, de revisão.

\section{A FOTOGRAFIA FAMILIAR E O CINEMA}

A fotografia familiar como recurso que leva ao relato, o qual o narrador anota a partir de Proust e Benjamin, é um elemento que aparecerá também 
em Respiração artificial, o romance que Piglia (1987) está escrevendo em paralelo a todas as passagens mencionadas até aqui. "Avança a história", escreve ele em 14 de abril de 1978: "a história para mim começa dez anos atrás. Eu tinha publicado meu primeiro livro e ele me mandou uma foto e uma carta" (PIGLIA, 2017, p. 76). Esta é uma versão preliminar da abertura desse romance: "Dá uma história? Se dá, começa há três anos. Em abril de 1976, quando é publicado meu primeiro livro, ele me manda uma carta. Com a carta vem uma foto, eu no colo dele: nu, estou sorrindo, tenho três meses e pareço um sapinho. [...] A foto é de 1941; atrás ele havia escrito a data" (1987, p. 11).

A passagem remete não apenas à fotografia recusada pela tia do narrador de Proust, mas também à reflexão anterior presente no diário, aquela do romance argentino e sua relação com a autobiografia. Essas duas linhas de exposição da visualidade convergem na reflexão mais ampla sobre a "figura imaginária do escritor" e sua tensão com a construção de uma "imagem pública”. O romance Respiração artificial é construído na narração do terceiro tomo dos diários como o movimento decisivo por parte do narrador na construção de sua "imagem pública", de sua figura de escritor. O acompanhamento das entradas do diário mostra que não é por acaso que o romance inicia com a evocação de uma fotografia familiar - é a marca do gênero e a indicação de que o autor trabalha a partir de uma tradição que ele próprio define como decorrente do campo autobiográfico.

Logo surge um contraste entre essa solicitação da visibilidade fotográfica do familiar e a reiterada questão da visibilidade do escritor como figura pública. Na anotação de 22 de setembro de 1980, o narrador manifesta dúvidas a respeito da qualidade da capa do romance, o uso das cores, em suma, a materialidade visível do artefato (PIGLIA, 2017, p. 129). Na sexta-feira da mesma semana, anota: "Vou com frequência ao cinema nesses últimos dias para esquecer a realidade. Hoje Os doze condenados de Robert Aldrich" (p. 130). O diário mostra essa alternância na solicitação do visível - momentos que dão conta da tarefa árdua de construção de uma imagem pública, com os livros, as aulas, conferências e aparições na imprensa, e momentos que dão conta de uma obliteração momentânea da autovisibilidade, por via da imagem socialmente compartilhada do cinema. Nessa mesma sexta-feira, o narrador escreve que foi à editora responsável pela primeira edição de Respiração artificial para discutir as "exigências a respeito de minhas aparições públicas para promover o livro. Esperança de que o livro tenha grande repercussão” (p. 130). 
Meses depois, surge uma anotação (15 de agosto de 1981) que apresenta essa repercussão como um fato e, consequentemente, como um problema: "o romance me colocou em uma posição visível", escreve o narrador, "na linha visível da literatura argentina", "tenho que voltar a uma posição alheia ao tumulto, voltar a ser inédito e desconhecido, pretendo não publicar nada nos próximos cinco ou seis anos" (PIGLIA, 2017, p. 150). Ou seja, sair da visibilidade da literatura argentina e retornar ao processo sempre inacabado de tornar visível uma obra, uma autofiguração ou automodelagem como escritor, pensando o último termo a partir da exposição pioneira de Stephen Greenblatt (1984) e o posterior comentário de James Clifford (1988, pp. 92-113). A articulação desses dois registros ocupa uma parte central na seção intitulada "Los finales", apresentada logo na sequência dos diários de 1982, o último ano apresentado na íntegra.

O narrador faz referência à recuperação da democracia a partir de 1983 e anota que, "agora" - colocando esse "agora” em itálico "todos eram escritores oficiais, reconhecidos, recebiam prêmios e eram entrevistados na televisão e assinavam colunas de opinião nos grandes jornais e suas fotos apareciam frequentemente nas revistas", os escritores agora eram "decorativos", continua ele, "insignificantes mas valorizados", respondendo ao imperativo cultural mais importante da época, "figuração ou morte": todos queriam aparecer, continua ele, "fazer-se ver", e os autores agora "eram mais importantes que seus livros, o que estava certo, pois seus livros eram tão insignificantes que uma foto no suplemento cultural de um jornal do interior valia mais que três ou quatro de seus livros publicados" (PIGLIA, 2017, p. 160). Esse cenário apresentado pelo narrador dos diários mostra uma ênfase particularmente argentina para aquilo que, entre tantos outros, também Beatriz Sarlo (2007, pp. 20-21) denominou "guinada subjetiva", frisando o papel das técnicas de visualidade nesse processo: "vivemos uma época de forte subjetividade e, nesse sentido, as prerrogativas do testemunho se apoiam na visibilidade que 'o pessoal' adquiriu como lugar não simplesmente de intimidade, mas de manifestação pública”, escreve a autora, e continua: "Isso acontece não só entre os que foram vítimas, mas também e fundamentalmente nesse território de hegemonia simbólica que são os meios audiovisuais".

É precisamente tal "hegemonia simbólica” que está em questão nos diários de Renzi/Piglia quando o imperativo "figuração ou morte" é posto em primeiro plano. Nesse ponto dos diários, o narrador já não diz "eu”, como 
nas anotações prévias, de 1976 a 1982, mas faz referência a Renzi, aquele que vive. "Renzi percebeu com clareza que uma época havia terminado e que uma cultura havia sido derrotada", prossegue o narrador, "antes, pensava Renzi, podíamos circular nas margens ligados à contracultura, ao mundo subterrâneo da arte e da literatura, mas agora éramos todos figurinhas de um cenário empobrecido e devíamos jogar o jogo que dominava o mundo" (PIGLIA, 2017, p. 160). Um conjunto de camadas forma essa complexa conclusão a que chega o narrador a respeito de seu contínuo processo de autorreconhecimento e de projeção social de sua figura de escritor. Em primeiro lugar, existe o distanciamento temporal marcado na seção "Los finales”: o narrador está, aproximadamente, em março de 2015 e resgata aquilo que vem imediatamente depois de 1982, o ponto em que decide interromper a transcrição cronológica dos diários. Em segundo lugar, existe esse "agora" da experiência que é marcado no discurso, marcado no nível do significante (agora), mas que é deliberadamente mantido em seu nível de invenção, de projeção ficcional, fabulatória, uma vez que faz parte da elaboração encantatória do narrador, posicionado, como se disse, em março de 2015. Para reforçar esse deslocamento e essa ambiguidade do registro, Renzi, aquele que vive, agora está distanciado pela terceira pessoa e não ocupa mais a posição do "eu" no enunciado.

\section{VISIBILIDADE DO ESCRITOR}

Toda essa construção de bastidor serve - na minha perspectiva aqui - para intensificar aquela dinâmica do visível que é exposta no início da anotação: Renzi percebe com clareza, vêaquilo que outrora estava obscuro, um movimento que metonimicamente absorve a abertura do momento político argentino. Essa renovação da visibilidade, contudo, acarreta uma banalização da figura do escritor, uma espécie de desequilíbrio daquela dinâmica prévia entre a automodelagem a partir de uma obra feita em segredo e o imperativo da aparição pública. "Figuração ou morte", escreve o narrador, ou seja, não temos escolha a não ser aparecer, figurinhas em um cenário, a maquete que faz ver o sistema literário do momento, uma encenação com lugares marcados que são momentaneamente ocupados. Não importa o livro publicado - ou seja, o fruto da automodelagem árdua e secreta - e sim a fotografia no suplemento cultural - a momentânea ocupação de um lugar no cenário.

Essa estratégia de deslocamento daquele que vive em direção à terceira pessoa é um tema constante nos diários. Uma de suas elaborações 
mais aprofundadas está em uma anotação de 1980, na qual o narrador comenta suas leituras de Wittgenstein por conta das aulas que oferecia nos grupos fechados de estudos que coordenava na época. Essa anotação de 1980 parece preparar o terreno para a retomada da posição em terceira pessoa de Renzi, que reencontraremos na seção "Los finales". O narrador anota, em 3 de novembro: "Passo todo o fim de semana preparando as aulas sobre Wittgenstein" (PIGLIA, 2017, p. 131), e continua:

[...] aquilo sobre o qual se deve calar é a experiência ética; o significado da vida não pode ser expresso com a linguagem dos fatos (nesse espaço selocaliza a ficção e especialmente o romance como gênero pós-trágico). Só podemos nomear as coisas que ocorrem a outras pessoas, nossa própria experiência vivida, nossa existência, nossa sensação do passar do tempo estão muito próximas de nós para ser visíveis de um modo externo (por isso a impossibilidade e a fascinação de diários pessoais como este); esse mundo constitui o objeto de preferência do romance, a narração coincide com a evocação dessas experiências incomparáveis. Só podem ser mostradas - no sentido de Wittgenstein, mas também de Henry James - porque a experiência vivida é incomunicável. Daí a premissa de Brecht, viver em terceira pessoa.

Em linhas gerais, o narrador afirma que a visibilidade da experiência imediata só se dá a partir de uma vida em terceira pessoa, reconstruída $a$ posteriori na chave do estranhamento - algo que se aproxima das ideias propostas por Émile Benveniste (2005, pp. 284-293) em seu célebre ensaio de 1958, "Da subjetividade na linguagem". O Renzi que retornará na seção seguinte, "Los finales", é a solução direta do narrador do diário a essa questão problemática da visibilidade do vivido. O elemento a ser ressaltado aqui é que o narrador deliberadamente coloca em questão também a visibilidade da figura do escritor - suas aparições públicas, suas fotografias nos suplementos, a materialidade de seus livros -, com o intuito de adensar sua permanente reflexão crítico-filosófica acerca do tema.

As fugas para o cinema, nessa perspectiva, não são meros registros cotidianos do diário, com o intuito de gerar o efeito de uma vida cumulativa, repetitiva. Pelo contrário, as fugas para o cinema são balizas narrativas fundamentais para a consolidação desse duplo registro do visível nos diários, um registro que deve dar conta tanto do abandono quanto do empenho, da resignação e da combatividade, da automodelagem e da aparição pública. É na obscuridade da cena do cinema que se dá, narrativamente, a clareza dessa situação ambígua do narrador dos diários. 


\section{UM DIA NA VIDA}

Já no interior da longa seção intitulada "Um dia na vida" - que o narrador, ainda na seção "Los finales", qualifica como sua tentativa de "micro-história" (PIGLIA, 2017, p. 161) - lemos: "Pediu que parasse o carro diante do cinema Atlas [...] entrou na sala e sentou para ver Pulp Fiction de Tarantino, que tinha estreado na semana anterior, eseus amigos mais jovens estavam encantados pelo descobrimento de um filme feito por um cinéfilo que renovava a sétima arte" (PIGLIA, 2017, p. 214). Isso nos posiciona por volta de 25 de fevereiro de 1995, uma vez que a data de estreia do filme de Tarantino na Argentina foi 16 de fevereiro. Encontramos uma cena antiga, recorrente, amplamente reutilizada: o narrador vai ao cinema. Contudo, a informação prévia que leva com ele é dada por uma nova geração, "amigos mais jovens", que falam de uma renovação da narrativa e da visualidade, algo que o narrador está prestes a pôr à prova.

"Só os filmes permitiam a Renzi deixar de pensar nas aulas ou nas conferências que tinha dado e que o deixavam sempre acelerado, sem poder parar de pensar" (PIGLIA, 2017, p. 214), escreve o narrador e, logo em seguida, apresenta uma descrição do seu método de trabalho para as aulas e para as conferências, ressaltando o regime de visibilidade que deve presidir esse trabalho para que ele ocorra da forma desejada:

\footnotetext{
Dava aulas com algumas notas e referências escritas em uma folha de papel branco tamanho carta, um quadro sinóptico [saliento o significante] dos temas que pensava expor, mas nunca podia consultar, em geral improvisava tratando de manter o interesse do público, sem baixar a vista para ver as notas, porque rapidamente perdia a concentração, de modo que uma aula o deixava paralisado ao sair e não podia deixar de dar voltas em torno dos mesmos temas, salvo se entrasse na aura escura do cinematógrafo, que o levava a outra dimensão, o cinema é o divã do pobre, quem disse isso?, foi Sartre?, não foi Sartre, o nome do filósofo francês lhe escapava (PIGLIA, 2017, p. 214).
}

A ideia do cinema como divã do pobre já havia aparecido na anotação de 22 de agosto de 1980, mas a indicação de autoria era segura: Gilles Deleuze (PIGLIA, 2017, p. 126). Essa ideia, na verdade, vem de um texto de Félix Guattari (1975, pp. 96-103).

A dinâmica das aulas e das conferências - ou seja, a cena de exposição máxima do escritor como figura pública - gera um excesso que só pode ser elaborado na cena obscura do cinema, na qual o escritor se encontra invisibilizado, reposicionado como mero olho passivo. Não é gratuita a aproximação da aula e da ida ao cinema nessa passagem dos diários, pois o 
efeito textual que gera é precisamente o de frisar a dupla correspondência entre esses dois registros. Além disso, Pulp Fiction merece um desenvolvimento que nenhum outro filme recebera até então nos diários: permite ao narrador revisitar a narrativa policial, a teoria do iceberg de Hemingway e chegar à definição de que se trata de um "filme pré-verbal, mas intensamente falado, com diálogos contínuos e brilhantes que não têm função narrativa e, por isso, são belos e inesquecíveis" (PIGLIA, 2017, p. 216). Não se trata, portanto, de apenas um comentário sobre um filme da moda, embora esse registro midiático da visibilidade esteja integrado ao comentário. Pulp Fiction funciona como uma espécie de plataforma privilegiada para a revisitação - a retomada diferida - de inúmeros pontos desenvolvidos não só no terceiro tomo, mas em toda a extensão do registro diarístico de Renzi/Piglia.

Por fim, um último resgate, da última seção do terceiro tomo dos diários, "Dias sem data”, em sua maioria referentes à rotina de Ricardo Piglia em Princeton. O narrador começa a frequentar uma academia de boxe, cujo instrutor é um "velho cubano exilado" que lhe dá a seguinte lição: "no pugilismo, o estilo depende da visão e da velocidade, ou seja, daquilo que ele chama, 'cientificamente', a visão instantânea” (PIGLIA, 2017, p. 268). De imediato, a lição insólita do instrutor de boxe remete a um conjunto de declarações que o narrador vem fazendo ao longo do terceiro tomo dos diários. A lição do instrutor de boxe é, ao mesmo tempo, estranha e familiar - gerando aquela sensação de inquietude teorizada por Freud (2010, pp. 328-376) e já tão repisada pela crítica literária (LYDENBERG, 1997, pp. 1.072-1.086). Isso ocorre porque a situação é insólita - o narrador treinando boxe com um cubano em Princeton - mas seu conteúdo é familiar, ou seja, a mensagem que oferece é reconhecível e diz respeito à relação entre estilo e visualidade. Dois dias depois, o narrador anota:

[...] releio o Diário de Stendhal. Recordo a visita à biblioteca de Grenoble com Michel Lafon. Nos sótãos tive acesso ao original do diário. [...] Stendhal acompanha com desenhos as cenas que narra em seu diário. Conta um jantar com amigos e logo faz um esboço minucioso da sala e da disposição dos convidados. Tinha uma imaginação espacial, cartográfica. [...] Anota no diário, em 23 de agosto de 1806: "eis aqui a razão por que acredito ter algum talento: observo melhor que ninguém, vejo mais detalhes, vejo com mais acerto, inclusive sem necessidade de fixar a atenção". O diário de Stendhal, outro exercício de "visão instantânea" (PIGLIA, 2017, p. 269). 
O diário tem a qualidade única de permitir esse deslocamento de uma cena a outra, extraindo potência estética da tensão gerada pelo atrito de duas cenas - o escritor-boxeador de um lado, o escritor-figura-pública de outro, manipulando o diário original de Stendhal. Mais uma vez a articulação dos dois registros dessa figura se dá a partir de uma solicitação do visível, uma "visão instantânea" que é tanto educação do corpo - seja no boxe, seja na doença - quanto ferramenta de leitura utilizada para abrir os mais variados artefatos, de Stendhal a Pulp Fiction.

\section{$\overline{\text { REFERÊNCIAS }}$}

BAL, Mieke. The Mottled Screen: Reading Proust Visually. Stanford: Stanford University Press, 1997.

BENVENISTE, Emile. Problemas de linguística geral I. Trad. M. da G. Novak et al. Campinas: Pontes, 2005.

CLIFFORD, James. On Ethnographic Self-Fashioning: Conrad and Malinowski. In: Predicament of Culture: Twentieth-Century Ethnography, Literature, and Art. Cambridge: Harvard University Press, 1988, pp. 92-113.

FOUCAULT, Michel. Nietzsche, a genealogia, a história. In: Ditos \& escritos II: arqueologia das ciências e história dos sistemas de pensamento. Trad. Elisa Monteiro. Rio de Janeiro: Forense Universitária, 2010, pp. 260-295.

GREENBLATT, Stephen. Renaissance Self-Fashioning: From More to Shakespeare. Chicago: University of Chicago Press, 1984.

GUATTARI, Félix. Le divan du pauvre. Communications, "Psychanalyse et cinéma" (sous la direction de Raymond Bellour, Thierry Kuntzel et Christian Metz), v. 23, 1975, pp. 96-103.

LYDENBERG, Robin. Freud's Uncanny Narratives. Publications of the Modern Language Association of America, v. 112, n. 5, Oct. 1997, pp. 1.072-1.086.

OLMOS, Ana Cecilia. A narrativa argentina das últimas décadas ou acerca de como narrar os "delitos de sangue". Revista Letras, UFSM, n. 35, 2007, pp. 105-116.

PIGLIA, Ricardo. Respiração artificial. Trad. Heloisa Jahn. São Paulo: Iluminuras, 1987.

PIGLIA, Ricardo. Las tres vanguardias. Saer, Puig, Walsh. Buenos Aires: Eterna Cadencia, 2016a.

PIGLIA, Ricardo. Los diários de Emilio Renzi. Tomo II. Los años felices. Barcelona: Anagrama, 2016b. 
PIGLIA, Ricardo. Los diarios de Emilio Renzi. Tomo III. Un día en la vida. Barcelona: Anagrama, 2017.

SARLO, Beatriz. Tempo passado: cultura da memória e guinada subjetiva. Trad. Rosa Freire d'Aguiar. São Paulo/Belo Horizonte: Companhia das Letras/Editora da UFMG, 2007.

WAISMAN, Sergio. La obra invisible de Emilio Renzi: lugar incierto, tradición clandestina. Revista Iberoamericana, n. 258, 2017, pp. 73-86.

Recebido: 19/06/2019

Aceito: 12/09/2019

Publicado: 25/11/2019

Remate de Males, Campinas-SP, v.39, n.2, pp. 627-640, jul./dez. 2019 - 640 